\title{
Productos meteorológicos del NWC SAF
}

https://doi.org/10.31978/639-19-010-0.013

\author{
José Miguel Gallardo Fernández (jgallardof@aemet.es) \\ Xavier Calbet Álvarez ${ }^{1}$ (xcalbeta@aemet.es) \\ Llorenç Lliso Valverde² (jllisov@aemet.es) \\ Pilar Rípodas Agudo ${ }^{1}$ (pripodasa@aemet.es) \\ Miguel Ángel Martínez Rubio ${ }^{1}$ (mmartinez@@aemet.es) \\ Javier García Pereda ${ }^{1}$ (jgarciap@aemet.es) \\ Javier Sanz García ${ }^{1}$ (jsanzg@aemet.es) \\ José Alberto Lahuerta García ${ }^{1}$ (jlahuertag@aemet.es) \\ Alfonso Hernanz Lázaro ${ }^{1}$ (ahernanzl@aemet.es)
}

${ }^{1}$ AEMET / Departamento de Infraestructuras y Sistemas

${ }^{2}$ AEMET / Delegación Territorial en la Comunidad Valenciana

\section{RESUMEN}

Los datos que se extraen de los satélites son mucho más que meras imágenes individuales. Trabajando sobre ellas y combinando unas con otras podemos extraer una serie de productos muy útiles para el pronóstico inmediato o nowcasting. Con este fin, el NWC SAF (Satellite Application Facility on support to Nowcasting) genera y difunde los productos y servicios operativos de EUMETSAT, para lo que pone a disposición de los usuarios un software con el que poder generar las herramientas que a todo predictor le serán de suma utilidad cuando haya que tomar decisiones en un periodo de una a tres o seis horas.

PALABRAS CLAVE: predicción inmediata; NWC SAF; avisos meteorológicos; anticipación; observaciones.

\section{INTRODUCCIÓN}

Como el resto de los SAF, el NWC SAF tiene el propósito de proporcionar a los Servicios Nacionales de Meteorología de sus estados miembros y cooperantes, así como al resto del mundo, software o productos de satélite relacionados con el tiempo. El objetivo general del NWC SAF es el de proveer servicios operativos para garantizar el uso óptimo de los datos de satélites meteorológicos en predicción a muy corto plazo.

EINWC SAF está liderado por AEMET, aunque también forman parte de él Météo-France, SMHI (Suecia), ZAMG (Austria) y MeteoRomania.

Los productos que genera el NWC SAF se dividen en las siguientes categorías:

1) Nubes

2) Precipitación

3) Convección

4) Humedad e inestabilidad

5) Vientos

6) Interpretación automática de imágenes

7) Imágenes extrapoladas 


\section{PRODUCTOS DE NUBES}

Los productos de nubosidad son 4 y las clasifican según su composición, su tipo o la altitud de su tope:

- CMA (Cloud Mask): nos dice si el pixel es nuboso o no, aunque también detecta si hay cenizas volcánicas o presencia de hielo/nieve (información que no está disponible por la noche).

- CT (Cloud Type): nos permite hacer una clasificación rápida del tipo de nubes.

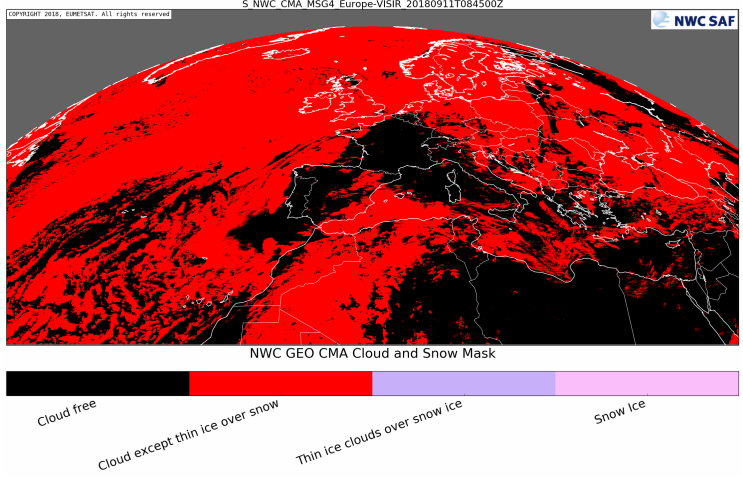

Figura 1. Producto CMA.

- CTTH (Cloud Top Height): se representa la altura del tope nuboso (en m y hPa), así como su temperatura.

— Utilidad de este producto: el 19 de febrero de 2017, a las 3 UTC, llovía de forma torrencial en Málaga. El echotop era de $8,5 \mathrm{~km}$ a la par que el CTTH mostraba una altura del tope nuboso de $11 \mathrm{~km}$.

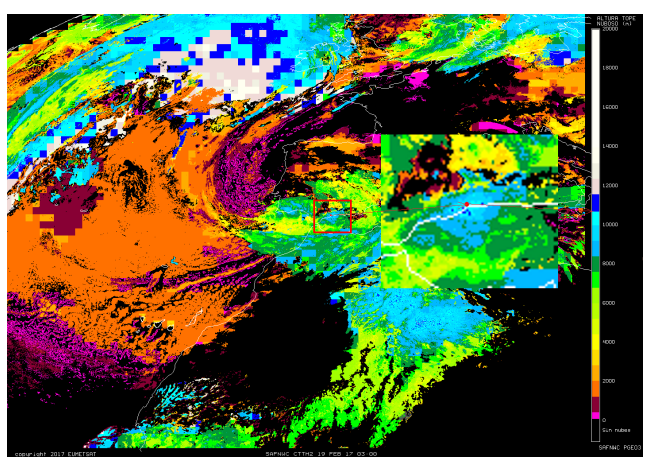

Figura 4.

Situación del 19 de febrero de 2017 a las 3 UTC.
- CMIC (Cloud Microphysics): proporciona información detallada sobre la microfísica de nubes. Este producto no está disponible durante la noche, salvo el Cloud Phase, que está disponible las 24 h del día.

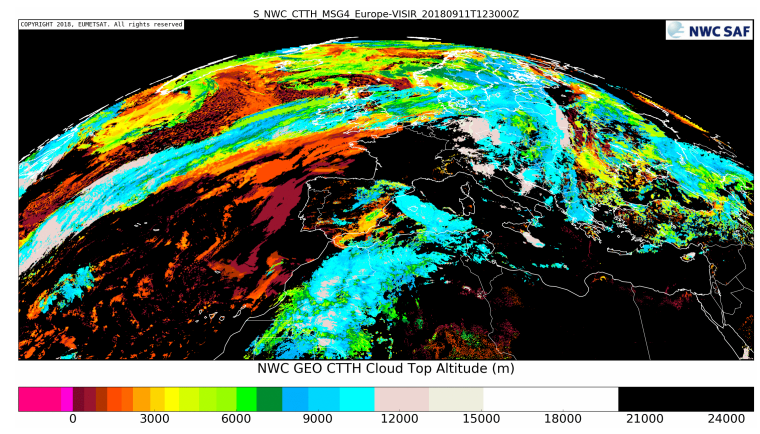

Figura 3. Producto CTTH.

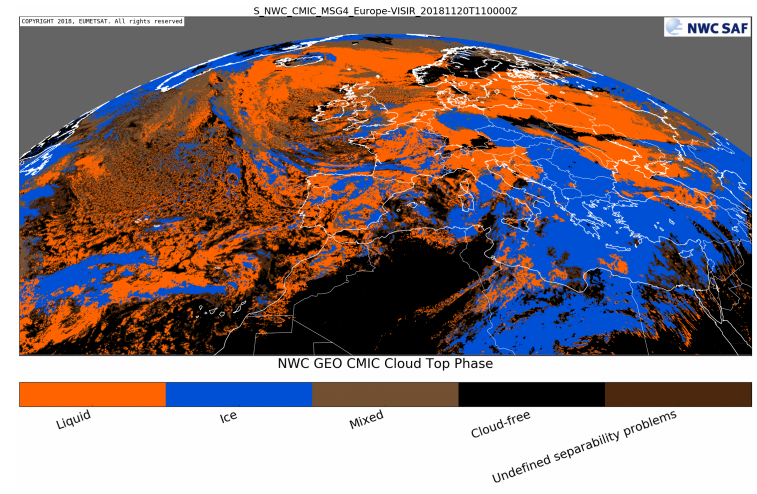

Figura 5. Producto CMIC. 


\section{PRODUCTOS DE PRECIPITACIÓN}

El NWC SAF genera dos tipos de productos de precipitación: el primero indica la probabilidad de que esté precipitando y el segundo refleja la intensidad de precipitación convectiva, instantánea o acumulada en 1 hora. Cada uno de estos productos se genera a partir de dos algoritmos diferentes. Uno de ellos utiliza principalmente los canales del satélite y el otro calcula los productos de precipitación a partir de los productos de microfísica. Así obtenemos un total de 4 productos:

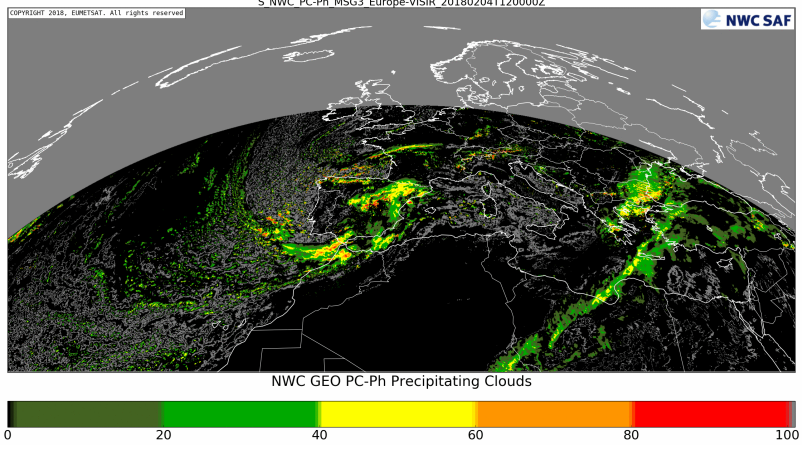

Figura 6. Producto PC-Ph.

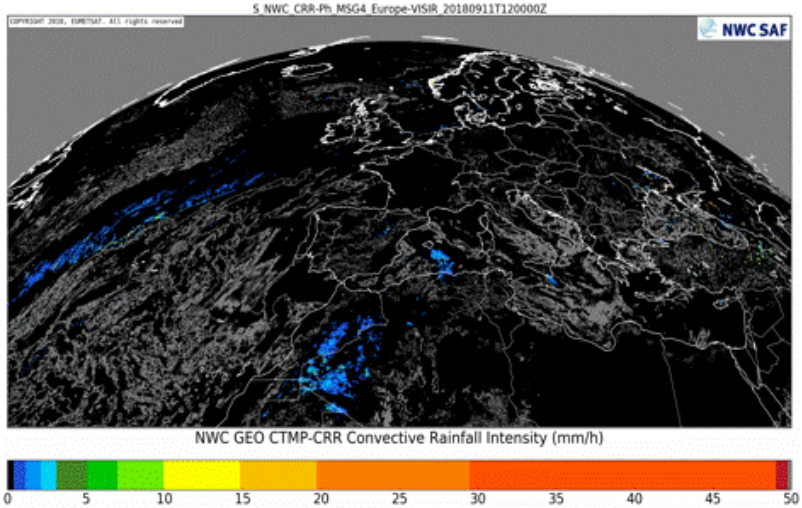

Figura 7. Producto CR-Ph.

Veamos algunos de ellos:

- PC-Ph (Probability of Precipitation based on Cloud Physical Properties): probabilidad instantánea de precipitación mayor o igual a $0,2 \mathrm{~mm} / \mathrm{h}$ en cada píxel.

- CR-Ph (Convective Rainfall Rate based on Cloud Physical Properties): proporciona información sobre la precipitación convectiva instantánea y la acumulada en 1 hora.

Estos productos utilizan el canal visible del satélite para integrar la microfísica de nubes, por lo que dependen del ángulo solar. Los productos son fiables cuando el ángulo solar es adecuado, por ello, en la figura 6, el producto se representa tan solo en una parte del globo pues, al ser febrero, la inclinación del Sol es mayor cuanto más al norte. A modo de ejemplo, compárense las imágenes del CR-Ph y del radar del 21 de julio de 2015. Cuando el ángulo solar es adecuado, la estimación de la precipitación concuerda muy bien con la imagen del radar, pero no ocurre lo mismo cuando el ángulo solar no es el adecuado.
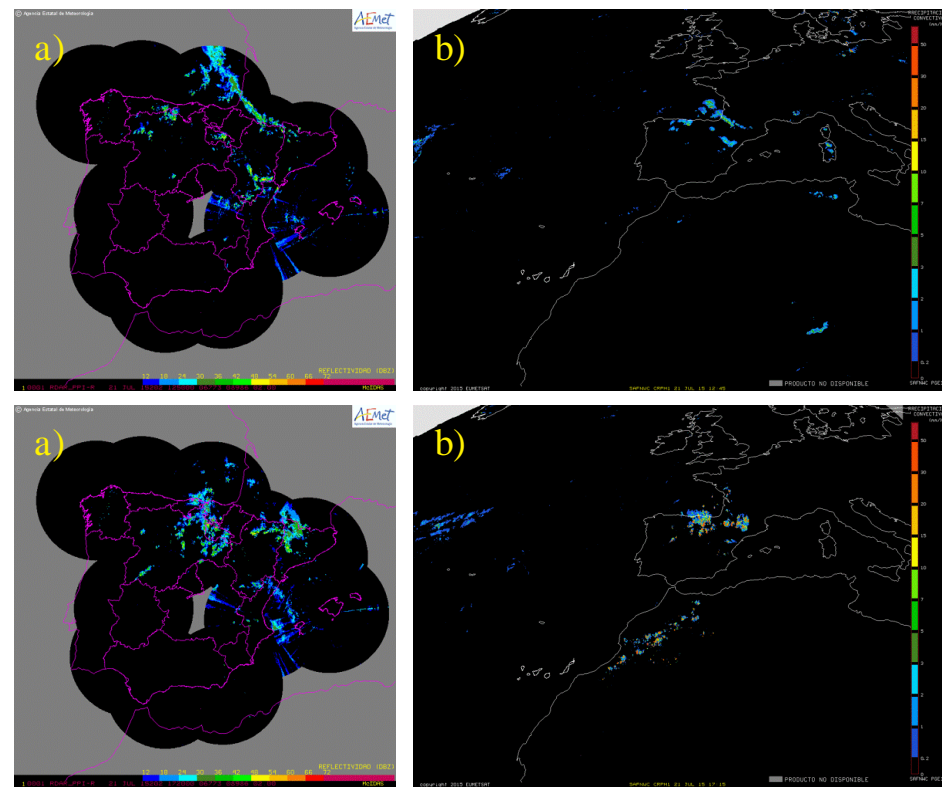

Figura 8.

Se puede observar como las zonas de precipitación del a) radar coinciden con las del b) producto $\mathrm{CR}-\mathrm{Ph}$. El ángulo solar en este caso era el adecuado.

Figura 9.

Sin embargo, unas horas más tarde, la imagen del a) radar coincide en la forma con las del b) producto $\mathrm{CR}-\mathrm{Ph}$, pero no en la intensidad de precipitación. En este caso el ángulo solar no era el adecuado. 


\section{PRODUCTOS DE CONVECCIÓN}

\subsection{Inicio de la convección}

- CI (Convection Initiation): proporciona la probabilidad de que un píxel se convierta en una tormenta dentro de 30 minutos (el objetivo a largo plazo es que sean 60 o 90 min).

— El 29 de agosto se registraron en la península 20710 descargas eléctricas. Compárese el mapa de descargas totales con la imagen del producto $\mathrm{CI}$.

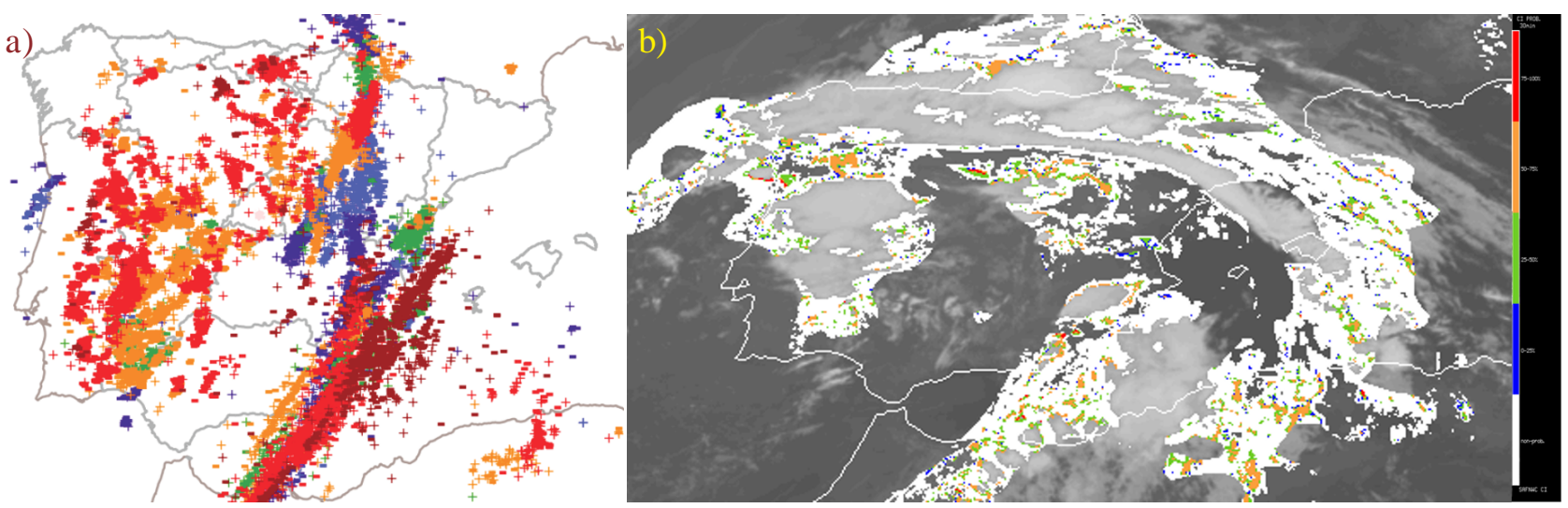

Figura 10. Se puede apreciar como a) las zonas donde se registraron rayos coinciden de forma aproximada con b) las zonas donde el producto CI nos indicaba que podría formarse una tormenta, aunque es cierto que hay falsos avisos.

\subsection{Trayectoria de las tormentas}

- RDT (Rapid Developing Thunderstorms): detecta la trayectoria y pronostica la evolución de la célula tormentosa.

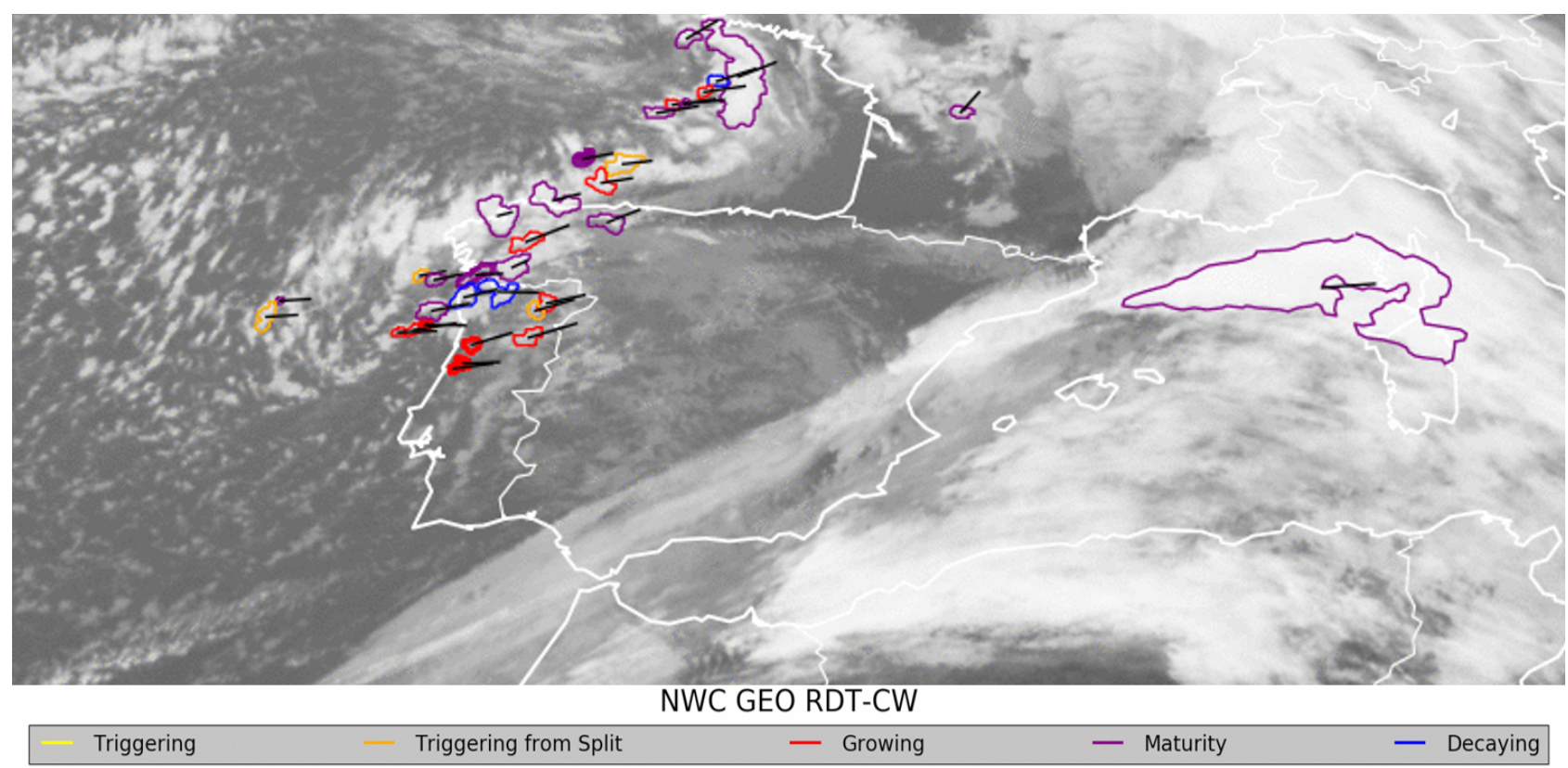

Figura 11. Producto RDT. Los códigos de colores corresponden a la fase en la que se encuentra la tormenta de su ciclo de vida. 


\section{PRODUCTOS DE HUMEDAD E INESTABILIDAD}

Estos productos nos indican la cantidad total de agua precipitable que hay en la columna de aire, así como en la capa baja, media y alta de la atmósfera, y varios índices de inestabilidad: Lifted Index, K index y Showalter.

- iSHAI (Imagery Satellite Humidity And Instability): proporciona información sobre el vapor de agua e inestabilidad en los píxeles de aire claro.

Este producto nos permite validar el modelo meteorológico al restar a la cantidad de agua precipitable observada por el satélite la prevista por el modelo. De esta forma podemos saber si en la previsión del modelo se ha sobrestimado o subestimado la cantidad de agua precipitable, lo que supone una herramienta imprescindible para el predictor.

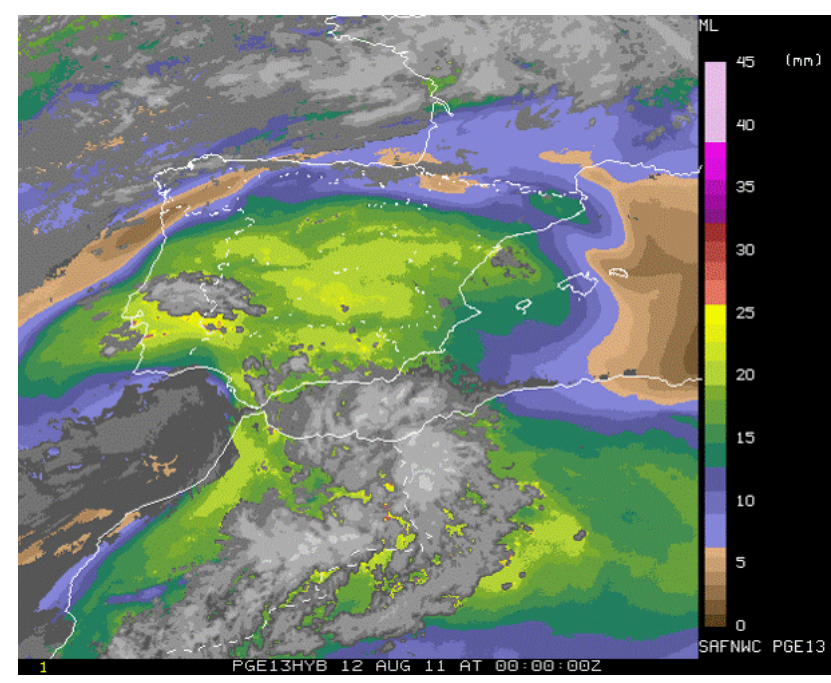

Figura 12. Producto iSHAI. Agua precipitable en capas medias.

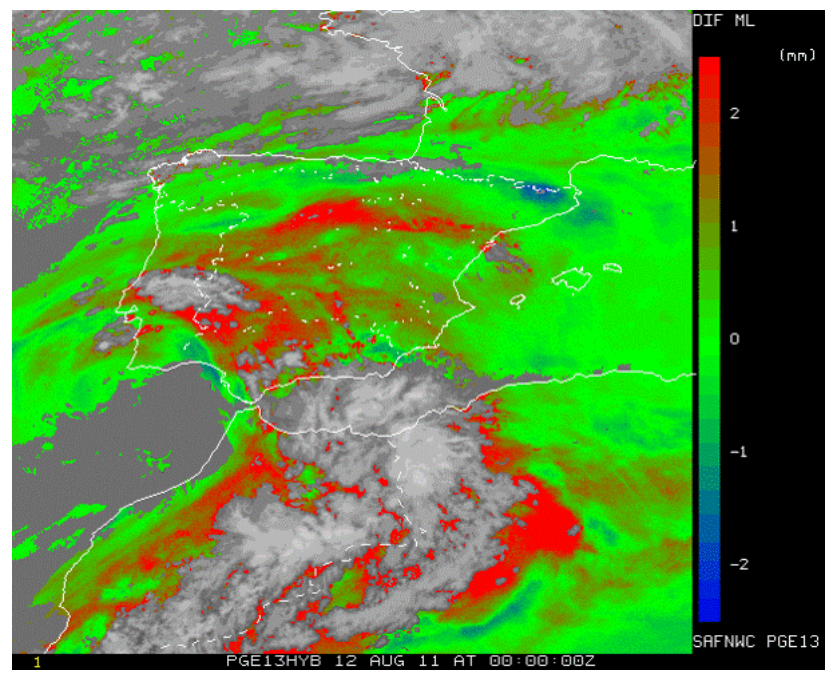

Figura 13. Como se puede apreciar, el 12 de agosto de 2011 el ECMWF subestimó la cantidad de agua precipitable (tonos rojos).

\section{PRODUCTOS DE VIENTOS}

Analizando el desplazamiento de las nubes y los gradientes de humedad en imágenes sucesivas de satélite, este producto nos indica la dirección y velocidad del viento a distintas alturas en la atmósfera.

- HRW (High Resolution Winds): determina la intensidad del viento (a diferentes alturas) en función del movimiento de las nubes y gradientes de humedad.

- Como ejemplo de la utilidad de este producto analizaremos el huracán Ophelia, una vez extratropicalizado y cerca de Irlanda. El 16 de octubre de 2018, a la 1:40 UTC, el producto HRW mostraba que los

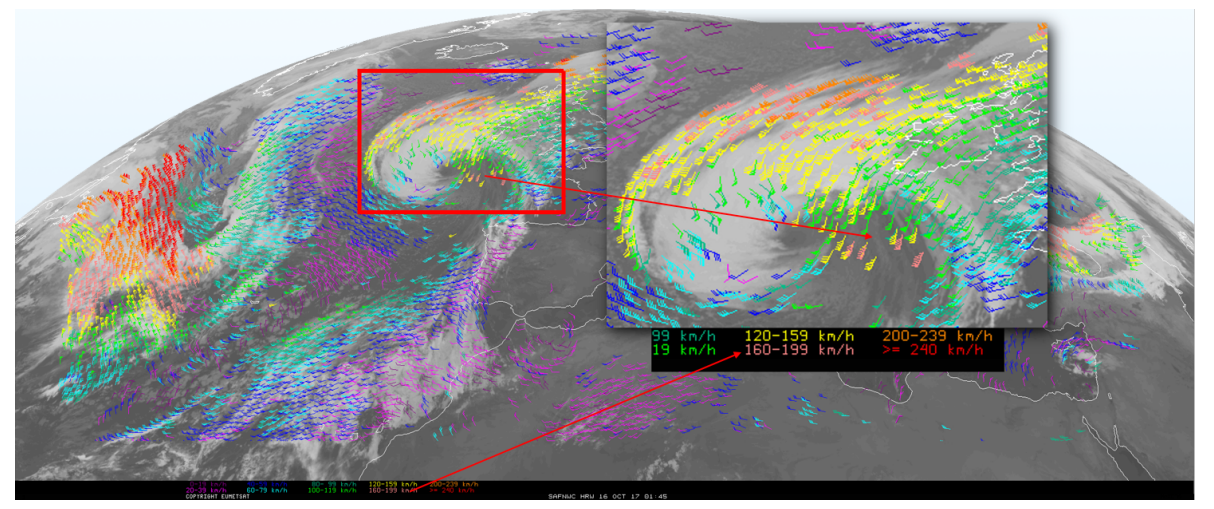

Figura 14.

Vientos asociados a la depresión extratropicalizada Ophelia. Producto HRW. 
vientos sostenidos asociados a la borrasca estaban entre los 160 y los $199 \mathrm{~km} / \mathrm{h}$ a una altitud de $1 \mathrm{~km}$ aproximadamente, lo que daba una idea de la intensidad con la que iba a impactar en suelo irlandés (figura 12). Finalmente la tormenta impactó en el sur de Irlanda con rachas que llegaron a $156 \mathrm{~km} / \mathrm{h}$ en Cork y a $175 \mathrm{~km} / \mathrm{h}$ en Fastnet Rock, según informaba la BBC.

- Pueden identificarse zonas de cizalladura vertical y horizontal gracias a este producto.

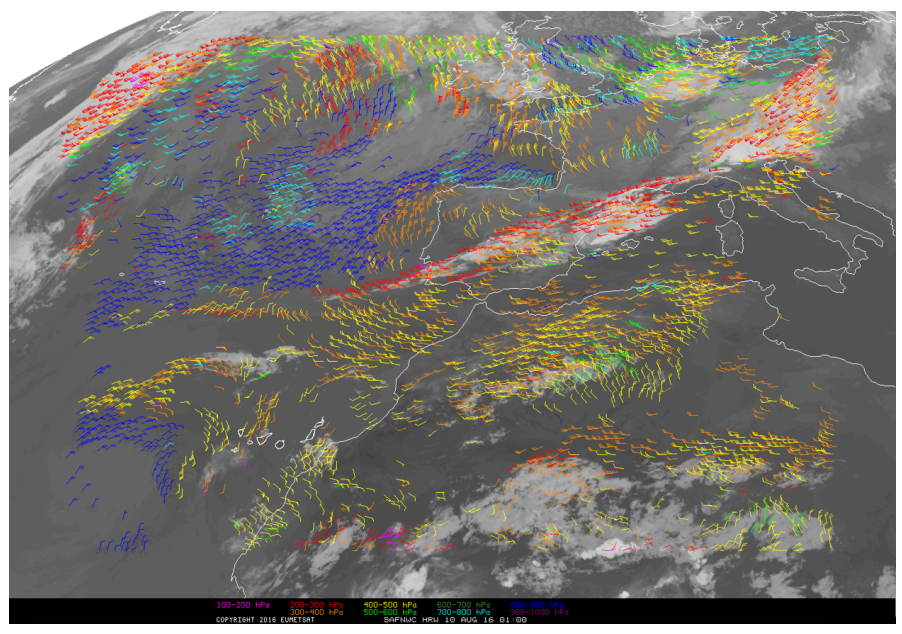

Figura 15. Se aprecia cizalladura vertical y horizontal (nivel 300-400 hPa) en el centro de la Península, y cizalladura vertical al sur del golfo de Valencia.

\section{INTERPRETACIÓN AUTOMÁTICA DE IMÁGENES}

\subsection{Turbulencia}

- ASII-NG (Probability of Occurrence of Tropopause Folding): proporciona la probabilidad de encontrar turbulencia debido a pliegues de la tropopausa. En un futuro se va a extender a otros fenómenos como la detección de ondas gravitatorias.

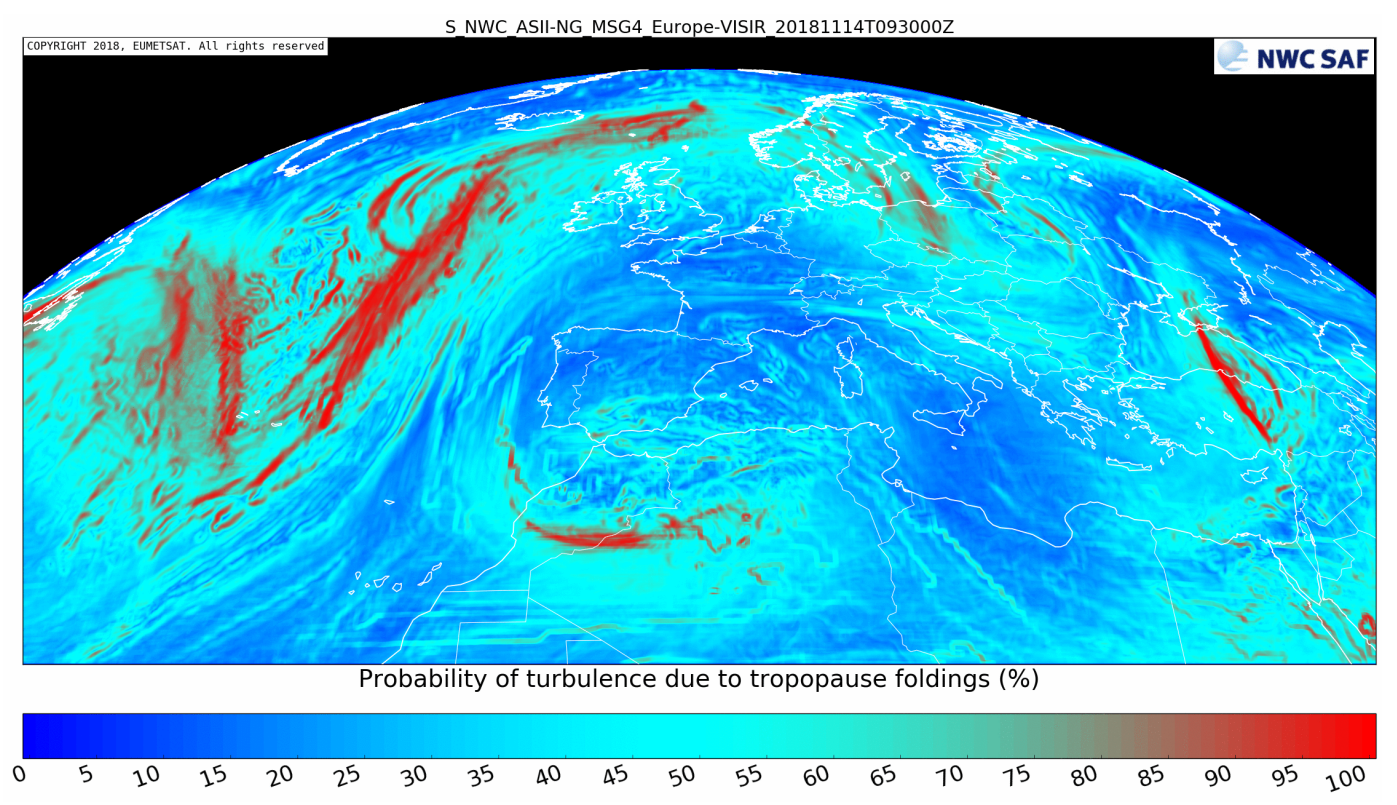

Figura 16. Producto ASII-NG.

\section{IMÁGENES EXTRAPOLADAS}

- $\operatorname{EXIM~(Extrapolated~Imagery):~este~producto~hace~una~extrapolación~cinemática~de~algunos~productos~}$ de nubosidad y precipitación gracias a los vectores del viento.

— El 5 de febrero de 2018 caía una nevada en Madrid que colapsaba carreteras y aeropuertos. 


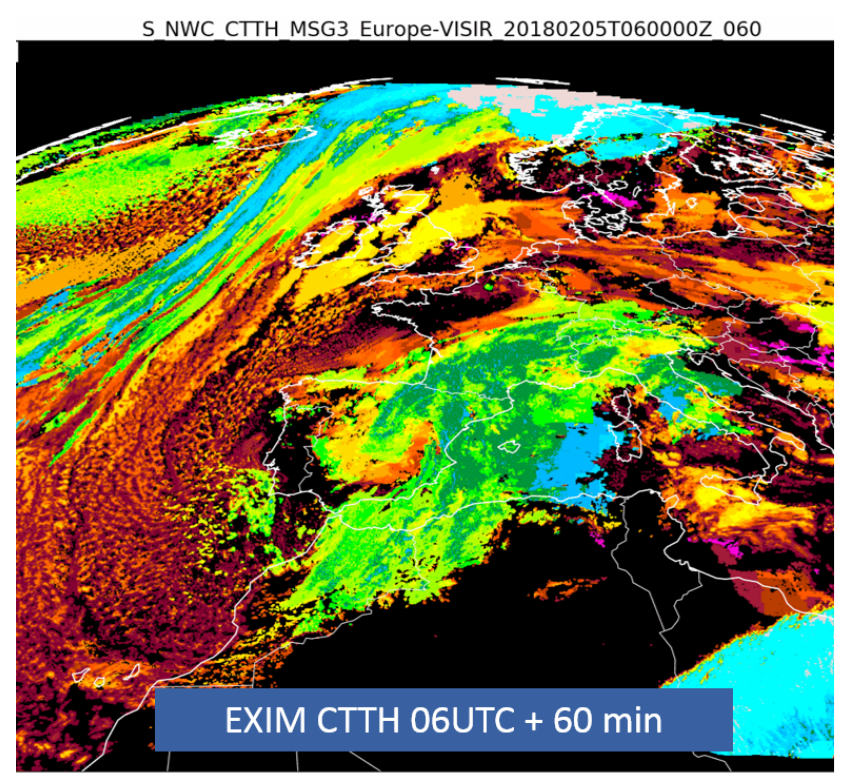

NWC GEO CTTH Cloud Top Pressure (Pa)

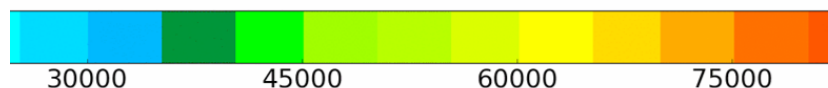

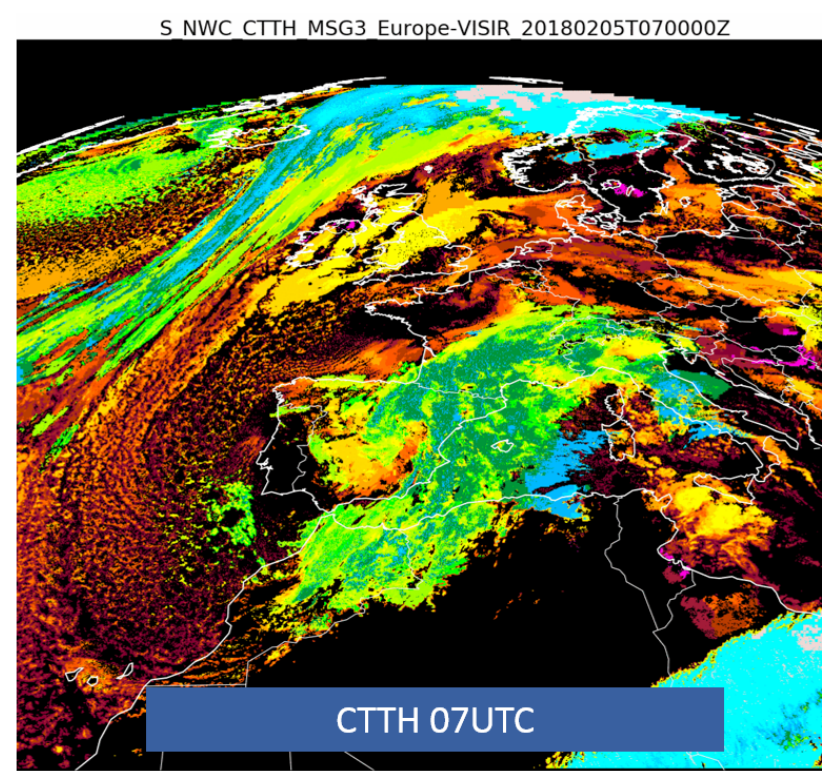

NWC GEO CTTH Cloud Top Pressure (Pa)

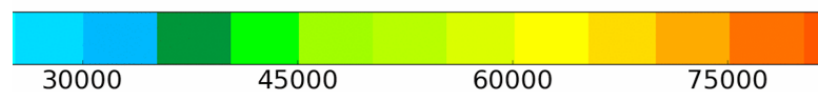

Figura 17. Compárese la imagen observada de las 7 UTC con la imagen extrapolada de las 6 UTC a las 7 UTC del 5 de febrero de 2018.

\section{9. ¿SON VÁLIDOS LOS PRODUCTOS PARA SU USO EN PREDICCIÓN?}

En general podemos afirmar que todos los productos generados por SAF de nowcasting han seguido un proceso de validación y han sido evaluados por EUMETSAT y otros agentes externos, garantizando un nivel de calidad suficiente antes de ser distribuidos a los usuarios. Hay que tener en cuenta que estos productos constituyen medidas indirectas de los fenómenos y estructuras que detectan, lo cual implica que cada uno tiene unas limitaciones que derivan de las limitaciones de los satélites para detectar dichos fenómenos y estructuras.

A continuación un breve resumen de la utilidad de cada uno de estos productos:

- Los productos de nubosidad se pueden usar con confianza. Son productos bien testados.

- Los productos de precipitación se pueden usar con confianza (conociendo sus limitaciones). Es un producto bien testado.

- El producto iSHAI se puede usar con confianza en situaciones de cielo despejado, pero con cuidado cerca o entre las nubes, ya que aquí puede dar medidas erróneas. Sin embargo podemos confiar si la medida persiste en el tiempo pese a estar cerca o entre las nubes.

- El producto HRW se puede usar con confianza. Es un producto bien testado.

- El producto ASII-NG hay que tener cuidado al usarlo, el producto no ha sido completamente validado.

- El producto CI se encuentra en pruebas, en su fase de desarrollo, pero es prometedor. La versión actual avisa de muchas falsas alarmas.

- El producto RDT se puede usar con confianza. Es un producto bien testado.

Una guía práctica para el predictor sobre el uso de estos productos en sus actividades está disponible en inglés en el siguiente enlace: http://www.nwcsaf.org/web/guest/practical-guide. 


\section{CONCLUSIONES}

Los productos del NWC SAF, conociendo las limitaciones de algunos de ellos, son una herramienta esencial para los predictores que necesitan tanto confirmar un diagnóstico como hacer un pronóstico para las próximas 3-6 horas. 